Comparative Philosophy Volume 1, No. 1 (2010): 53-77

Open Access / ISSN 2151-6014

www.comparativephilosophy.org

\title{
LOGICAL ANALYSIS AND LATER MOHIST LOGIC: SOME COMPARATIVE REFLECTIONS
}

\author{
MARSHALL D. WILLMAN
}

\begin{abstract}
Any philosophical method that treats the analysis of the meaning of a sentence or expression in terms of a decomposition into a set of conceptually basic constituent parts must do some theoretical work to explain the puzzles of intensionality. This is because intensional phenomena appear to violate the principle of compositionality, and the assumption of compositionality is the principal justification for thinking that an analysis will reveal the real semantical import of a sentence or expression through a method of decomposition. Accordingly, a natural strategy for dealing with intensionality is to argue that it is really just an isolable, aberrant class of linguistic phenomena that poses no general threat to the thesis that meaning is basically compositional. On the other hand, the later Mohists give us good reason to reject this view. What we learn from them is that there may be basic limitations in any analytical technique that presupposes that meaning is perspicuously represented only when it has been fully decomposed into its constituent parts. The purpose of this paper is to (a) explain why the Mohists found the issue of intensionality to be so important in their investigations of language, and (b) defend the view that Mohist insights reveal basic limitations in any technique of analysis that is uncritically applied with a decompositional approach in mind, as are those that are often pursued in the West in the context of more general epistemological and metaphysical programs.
\end{abstract}

Keywords: Mohist Logic, compositionality, intensionality, idiomaticity

\section{INTRODUCTION}

Any philosophical method that treats the analysis of the meaning of a sentence or expression in terms of a decomposition into a set of conceptually basic constituent parts must do some theoretical work to explain the puzzles of intensionality. This is because intensional phenomena appear to violate the principle of compositionality, and the assumption of compositionality is the principal justification for thinking that an analysis will reveal the real semantical import of a sentence or expression through a

WILlMAN, MARSHALL D.: Assistant Professor of Philosophy, New York Institute of Technology, Nanjing-China Campus. Email: mwillman@nyit.edu 
method of decomposition. In this regard, a natural strategy for dealing with intensional phenomena is to argue that there is a principled distinction to be drawn between extensionality and intensionality in natural language, and that the latter is really just a small, aberrant class of linguistic phenomena that poses no general threat to the thesis that meaning is basically compositional. Philosophical analysis, if properly construed as a decompositional enterprise, may then carry on unimpeded, provided that the entities or contexts being analyzed are not intensional (i.e., they are extensional), and are clearly distinguished from their more recalcitrant, but less common, intensional counterparts. In that way, compositionality can be said to hold its place as a plausible descriptive thesis about the semantics of natural language. ${ }^{1}$

Yet there is good reason to believe that this way of presenting the problem of intensionality is mistaken. The later Mohists, who may well have been the first in the world to attempt to furnish a systematic philosophical treatment of intensional phenomena, were aware of this, at least implicitly. The Mohists were keen observers of language, and their semantical investigations made them suspicious about the role of compositionality in the determination of the meanings of compound expressions. What they realized, and what we can subsequently learn from them, is that compositionality is not a principle to be taken for granted; it cannot be assumed a priori to hold of a definitive range of complex expressions that are distinguishable on the basis of their syntactical properties alone. While it may be fitting to characterize much of natural language meaning as compositional, it is incorrect to suppose that there can be any principled distinction between intensionality and extensionality in natural language.

The later Mohists' interest in intensional phenomena is thus more than a matter of historical curiosity. Fully explained, it draws our attention to fundamental limitations in Western techniques of philosophical analysis. Part of the picture that emerges of Western philosophy is one of a myopic vision of the nature of language that has misled philosophers into assuming that a sentence, expression, proposition, concept, or idea is perspicuously represented or understood only when it has been fully decomposed or resolved into its constituent parts. Part of my purpose in this paper is to explain why the Mohists found the issue of intensionality to be so important in their logical and

\footnotetext{
${ }^{1}$ I assume in this essay that any explanation of analysis firmly rooted in the decompositional conception invariably presupposes at least some version of the principle of compositionality. To analyze a complex idea or expression, in this view, it is both necessary and sufficient to identify the meanings of its constituent parts and the way in which they hang together. Compositionality maintains, in other words, that the meanings of wholes are determined by the meanings of parts in connection with any logical structures that are formed through their combination. For a stronger version of this basic idea, it is often argued that the structures or logical forms of the meanings of natural language expressions are tracked, systematically, by the compositionality of their syntax. Note that this is best considered "stronger" than the basic idea because one might acknowledge the plausibility or veracity of the compositionality of meaning while insisting that the combinatorial rules that govern the syntax of natural language expressions do not always mirror the logical forms of their meanings. Still, a logical analysis typically begins with a sentence, and this sentence will usually serve as a guide to the analysis itself. To the extent that it does, it should be possible to show that the rules governing the syntax of natural language sentences can be associated with determinate semantical operations that act on the meanings of grammatical constituents in precisely the ways in which these constituents are combined in the syntax.
} 
semantical investigations. But more importantly, I will defend the view that Mohist insights, in connection with a number of issues emerging out of the idiosyncrasies of the Chinese language, reveal obvious and important limitations in any technique of analysis that is uncritically applied with a decompositional approach in mind, as are those that are often pursued in the West in the context of more general epistemological and metaphysical programs.

\section{WESTERN CONCEPTION OF ANALYSIS}

Analysis in Western philosophy has, of course, been conceived and practiced in many different ways, and the decompositional conception is but one among many accounts that have been proposed or suggested over the ages. But it is not an exaggeration to say that the decompositional conception, more than any other, has exercised a profound influence on the minds of philosophers in the West. The British empiricists followed it in their analyses of complex ideas. ${ }^{2}$ It played a key role in the writings of Leibniz and Kant, ${ }^{3}$ and G.E. Moore adhered to it in the conception of analysis he developed in his major work Principia Ethica (1903). ${ }^{4}$ In point of fact, the decompositional conception

\footnotetext{
${ }^{2}$ See, for instance, Locke 1690, 291-3.

${ }^{3}$ Leibniz's well-known "containment principle" asserts that all judgments contain as parts a subject and a predicate, and an analysis of the logical relation that obtains between these two parts in a given judgment is a necessary step in the evaluation of its truth. For Leibniz, what makes a judgment true is that its predicate is logically contained within its subject, and the way in which we determine this is by a process of decomposing its parts into a sequence of identities (Leibniz, Gottfried 1690, 62). In an essay entitled "Primary Truths", Leibniz writes: "The predicate or consequent... is always in the subject or antecedent, and this constitutes the nature of truth in general, or, the connexion between the terms of a proposition, as Aristotle also has observed. In identities this connexion and inclusion of the predicate in the subject is expressed, whereas in all other truths it is implicit and must be shown through the analysis of notions, in which a priori demonstration consists" (Leibniz 1686, 30-4). The analysis of notions consists of reducing complex truths into primary truths by the aid of definitions. Kant's account of how we comprehend the meanings of judgments departs from Leibniz's in critical respects, chiefly in its claim that synthetic judgments may also be true, but the underlying conception of how we determine truth also requires that we resolve a judgment into the basic parts of subject and predicate (Kant 1787, 48-51 (A6-7/B10-1).

${ }^{4}$ The decompositional conception is implicit in Moore's conception of analysis, which Moore conceives as a process of providing a definition for a complex object (such as a proposition) by decomposing it, as it were, into its ultimate, constituent parts: "Definitions... which describe the real nature of the object or notion denoted by a word, and which do not merely tell us what the word is used to mean, are only possible when the object or notion in question is something complex. You can give a definition of a horse, because a horse has many different properties and qualities, all of which you can enumerate. But when you have enumerated them all, when you have reduced a horse to his simplest terms, then you no longer define those terms. They are simply something which you think of or perceive, and to any one who cannot think of or perceive them, you can never, by any definition, make their nature known (Moore 1903, 7). The "simplest terms" of which Moore speaks were themselves regarded as indefinable, the notions "good" and "yellow" being primary examples: "“G]ood' is a simple notion, just as 'yellow' is a simple notion; that, just as you cannot, by any manner of means, explain to any one who does not already know it, what yellow is, so you cannot explain what good is" (1903, 7). In Moore's view, the
} 
has had a profound influence even on those thinkers who have struggled adamantly to articulate methodologies of a very different kind. A rather different conception of analysis, often called logical analysis in connection with the development of modern symbolic logic in the work of Frege and Russell, involves techniques of formal transcription or translation that have little to do with the decompositional conception per se. Generally speaking, an analysis may be considered "logical" when its concern is with the translation of statements of ordinary language into the theoretical framework of a formal or semi-formal language whose logical notions are perspicuously represented and set apart from its non-logical ones. On the other hand, this practice of interpreting or translating is very often undertaken with the tacit belief that a decomposition of one form or another is the goal of any formal representation of meaning.

As an example this, we can note that in Western analytic philosophy, it is not at all atypical to treat the concatenation of elements in complex expressions in terms of predicate conjunction, which is really a form of decomposition. This is especially the case with respect to complex nominal expressions. Thus, the sentence 'Jill met a large, angry dog' would be represented in first-order predicate logic as follows:

(1) $(\exists x)(\operatorname{Met}(\operatorname{Jill}, x): \&: \operatorname{Large}(x) . \& . \operatorname{Angry}(x) \& \operatorname{Dog}(x))$

Each of the words in 'large, angry dog' is glossed as a simple predicate and joined with the others by the logical operator for conjunction, represented by the ampersand symbol, '\&'.

Complex verb phrases are more difficult to handle, but predicate conjunction still seems presupposed as a basic principle in most cases. For instance, to represent the sentence 'Jill runs hastily', Pietroski considers an event-analysis in connection with predicate conjunction:

\section{(2) $(\exists e)($ Agent $(e, J i l l) . \& . R u n(e) \& \operatorname{Hasty}(e))$}

The variable ' $e$ ' is for events, and events are assumed to be capable of instantiating a variety of properties: they have agents, objects, manners, etc., and occur at specific times and places. In this case we have an event whose agent is Jill, since Jill is the one who runs hastily. The event is also a running event and a hasty one (Pietroski 2000, 161-76).

Even Russell's theory of descriptions, which is said to facilitate the elimination of problematic terms or expressions, is still reasonably construed as a kind of decompositional analysis. Consider a natural language application of this theory to descriptive phrases involving relative clauses, such as 'The $F$ that is $G$ '. On this point, a Russellian analysis of the sentence:

process of providing a definition must eventually arrive these simple, indefinable parts, for otherwise the analysis would go on ad infinitum and the definition would be impossible. 


\section{(3) The $F$ that is $G$ is $H$}

has the following logical form:

(4) $(\exists x)((F x \& G x) \&(\forall y)(((F y \& G y) \rightarrow y=x) \& H x))$

This analysis is Russellian in that it replaces the analysandum with a quantified formula in which the descriptive phrase has been eliminated. But it is also a decomposition because the predicates embodied in the descriptive phrase 'The $F$ that is $G$ ' have been resolved into a formula that represents them as a conjunction of predicates.

These analyses, it should be noted, are not at all implausible, for they furnish a straightforward method for dealing with entailment relations-something arguably involved in the comprehension of any natural language sentence. If one knows, for example, that the sentence 'Jill ran angrily and hastily' is true, then one also knows that the sentences 'Jill ran', 'Jill ran angrily', 'Someone ran angrily', 'Someone did something', etc., are true. We also seem capable of recognizing second-order entailments: 'Running was instantiated by Jill', 'Running was instantiated by someone', and so on. Competency with respect to logical entailments is, arguably, a precondition for the comprehension of sentence meaning. Moreover, Russell's theory has benefits of its own: it can be utilized as an analytic tool to eliminate expressions referring to metaphysically dubious entities, and it can help us deal with problems of scope and ambiguity. On the other hand, as a general analytical methodology, the business of explaining entailment relations, ambiguity, and scope in terms of predicate conjunction will clearly not work for many of the arguments adduced in the Mohist Canons. This is because these arguments are intensional in content and resist any easy compositional representation. Moreover, a significant number of these arguments involve intensional contexts whose contents are arguably non-epistemic, and are therefore not capable being dismissed for reasons pertaining to the complications imposed by the involvement of mental states.

\section{MOHIST LOGIC AND INTENSIONALITY}

The Mohist writings that I am concerned with in this essay are those in which the study of logic and language play a central role. They are the entire four chapters of Book 10 and the first two chapters of Book 11 of the $\mathrm{Mo}$ - $\mathrm{Zi}$ (chapters 40-5, collectively referred to as the Mohist Canons). The chapters of Book 10 are known by the titles Jing-Shang (经上, Canons I), Jing-Xia (经下, Canons II), Jing-Shuo-Shang (经说上, Expositions of the Canons I), and Jing-Shuo-Xia (经说下, Expositions of the Canons II). In Book 11, we have the Da-Qu (大取, Major Illustrations) and the Xiao-Qu (小取, Minor Illustrations). The text of the Canons leaves a great deal unsaid; there are missing segments and obvious textual errors, and interpretations of a number of critical 
passages have exhibited widespread disagreement. In this essay I will follow the numbering system presented in Graham, A.C., 2003 [1978], which pairs each Canon with its corresponding Exposition and identifies the passages from each pair by numbers prefixed with the letters A and B. (For instance, passage B40 of the Canons is from Canons II.) Graham's work also reconstructs the Da-Qu (大取) and the Xiao-Qu (小取) into a single corpus entitled Names and Objects (NO). (Graham 2003)

The Mohists seem to have been wrestling with intensional phenomena from a variety of different points of view. In so doing they appear to have examined a number of basic logical operations that are utilized today as tests of intensionality. This might seem anachronistic; after all, I am imposing certain ideas on the Mohists that many would think could not have been realized without the jargon of $20^{\text {th }}$ century analytic philosophy. Yet there is a lot of textual evidence to support it, and a lot that can be reconstructed in the background. To begin with, the Mohists seem to have had at least an implicit awareness of the basic thesis (commonly attributed to Bertrand Russell) that the grammatical form of a sentence or an expression cannot be assumed to be a reliable indicator of its underlying logical form. To be sure, the Mohists quite likely had no rigorous sense of what it means for a sentence or expression to have a logical form, to say nothing of the formal symbolic apparatus that is generally necessary to perspicuously represent it. But they did have a strong sense of the relevancy of treating linguistic names and expressions as distinct objects of study, and they had clear ambitions to introduce greater rigor into the standards of grammaticality. ${ }^{5}$

Moreover, they were aware of the possibility that certain strings of characters whose constituents play analogous grammatical roles can nonetheless have very different conditions of satisfaction. That is the lesson we learn from an important later passage from the reconstructed text entitled Names and Objects $(N O)$ by A.C. Graham, which essentially compares the satisfaction conditions of two analogous assertions involving expressions that have the same grammatical form. The expressions are 'loving people' and 'riding horses':

Loving people requires loving all people without exception, only then is this called loving people. Not loving people does not require loving no people at all; it is (rather) not loving all people without exception, and by this it is called not loving people. Riding horses does not require riding all horses without exception; it is (rather) riding some horses, and by this it is called riding horses. But not riding horses does require riding no horses at all; only by this is it called not riding horses. These are cases in which something applies without exception in one case but not in the other. (NO17)

Evidently, the Mohists are pointing out here that the predicate 'loves people' is satisfied only by those who happen to love all people, whereas the predicate 'rides horses' is satisfied by anyone who happens to ride at least one horse. By the same token, the predicate 'does not love people' is satisfied by anyone who fails to love at

\footnotetext{
${ }^{5}$ According to A.C. Graham, the Mohists' use of the expression 'ye che' (也者) is used throughout the Canons as a form of quotation to talk about the meanings of key words and expressions (Graham 2003, 140-1).
} 
least one person, whereas the predicate 'does not ride horses' requires that one ride no horses at all. Even ignoring the added complications of the intensionality of the verb 'loves', we have here very different conditions:

'Jill loves people' is true iff Jill $\in\{x \mid(\forall y)(\operatorname{Person}(y) \rightarrow \operatorname{Loves}(x, y))\}$

'Jill rides horses' is true iff Jill $\in\{x \mid(\exists y)(\operatorname{Horse}(y) \& \operatorname{Rides}(x, y))\}$

'Jill does not love people' is true iff Jill $\in\{x \mid(\exists y)(\operatorname{Person}(y) \& \sim \operatorname{Loves}(x, y))\}$

'Jill does not ride horses' is true iff Jill $\in\{x \mid \sim(\exists y)(\operatorname{Horse}(y) \& \operatorname{Rides}(x, y))\}$

Notice, in spite of this, that the sentences 'Jill loves people' and 'Jill rides horses' have the same grammatical form; their constituents are playing the same basic grammatical roles. In classical Chinese, these sentences would be written simply as '藏 爱人' and ‘蔵乘马', respectively. Even if the Mohists did not possess a rigorous notation for dealing with these differences of logical form, they were certainly knowledgeable enough of the pitfalls of assuming that sentences with the same grammatical form should be given analogous semantical representations.

Now, if the Mohists knew that two sentences of identical form could have very different truth conditions, then they almost certainly sought out explanations for why, in particular, sentences containing intensional verbs appear to behave so differently from those without them. This would have been an integral part of their general methodological program. Indeed, there is some evidence that they were aware of the basic distinction between intensions and extensions; see Zong 2000, 221. ${ }^{6}$ If so, then they would have had some feeling for the idea that the truth of a sentence containing an intensional expression requires a consideration of the intension of this expression as well. In any case, it is hard to make sense of the Mohists' logical writings without assuming that they had at least an implicit understanding of intensional phenomena, if not an explicit one.

For instance, in passage B40 of the Expositions they seem to employ or presuppose a logical operation that many today would characterize as an intersubstitution of coextensive predicates:

（5）智狗重智犬, 則過。不重, 則不過。

\footnotetext{
${ }^{6}$ Zong claims that this distinction was grasped by the Mohists in their discussion of time and sameness. This is certainly debatable, but the text seems consistent with it. Note that the Mohists' awareness of an intension / extension distinction does not imply that they could not have rejected the possibility of a principled distinction between intensionality and extensionality in natural language. True, the possibility of understanding the basic nature of intensional phenomena seems to require that one first grasp the distinction between intensions and extensions. On the other hand, an acknowledgement of the presence of intensional phenomena in language need not be taken to imply the possibility of a principled distinction between intensionality and extensionality. There may be no such distinction; it may just be that the facts that distinguish the two are in some cases arbitrary or imprecise. Compare the notion of "child" with that of "adult." Except arbitrarily, one cannot identify an exact age at which one becomes an adult, and yet no one believes that a four year old should have voting privileges or a driver's license.
} 
To assert the identity of knowing dogs and knowing canines is a mistake; to not do so is not a mistake. ${ }^{7}$

This passage employs the terms 'gou' (狗, dog) and 'quan' (犬, canine), which the Mohists used as standard examples of ming (名, name), names that refer to the same thing, or predicates whose extensions are identical. That the Mohists were concerned with two names referring to the same thing is obvious from their discussion of sameness in A86 and elsewhere. They also clearly used the term 'ming' (名) for what we would today regard as predicates - no doubt in part because they did not distinguish predicates from singular terms. If we characterize this epistemically, then the Mohists seem to be asserting that the mental act of knowing what a dog is is not the same as the mental act of knowing what a canine is, for one's comprehension of the concept in each case is different. If this is correct, then in the Mohists' view, (7) does not follow from (6), in spite of the fact that all dogs are canines:

(6) Jill knows what a dog is.

(7) Jill knows what a canine is.

The intersubstitution of the predicate 'canine' for the predicate 'dog' is an invalid logical operation in the context of the intensional verb 'knows'. Indeed, if the Mohists did distinguish intensions from extensions, then their reason for why it does not follow from the fact that Jill knows dogs that she knows canines would have been that the intensions expressed by the predicates 'dogs' and 'canines' are not identical. They would have recognized that terms denoting these intensions are not logically interchangeable, and their proposition at B40 would have followed as a trivial consequence. $^{8}$

\footnotetext{
${ }^{7}$ Unless otherwise specified, the translations in this section and the next are my own. Though I have been greatly influenced by A.C. Graham, I have departed from his translations in many cases in favor of interpretations that I feel more closely track the original grammar of classical Chinese.

${ }^{8}$ It is not an incidental point, in this regard, that many commentators have misinterpreted this passage, assuming that it is inconsistent with the line in the Canons with which it is paired, and in need of emendation; Li 1969, 179, 194-5, He 1971, 151, 179, and Chen 1983, 21-22 are examples. (I have borrowed these sources from Zong 2000.) By contrast, Zong claims that B40 of the Canons contains a textual error, in that it omits a critical character for negation whose addition is necessary to square it with the putative explanation we find for it in the Expositions (Zong 2000, 215-7). In my opinion there is no inconsistency here; the explanation for the apparent discrepancy consists in the fact that the Mohists are simply talking about two different senses of 'knowing,' which they distinguish by the use of two different ideographs, 'zhi' (知) and 'zhi' (智). This is the passage at B40 of the Canons: “知狗而自谓不 知犬过也。说在重。” ("Knowing dogs while saying of yourself that you do not know canines is a mistake. This is explained by (the notion of) identity.") It cannot be a coincidence that the Mohists fail to repeat the use of '知' (zhi) in the line of the Expositions that corresponds to this passage (see (5) above), preferring instead the character '智' (zhi), for they do the same thing in B39 and elsewhere, and they explicitly distinguish their meanings in A3-6. In A5 they define '智' (zhi) as a form of knowing that involves being able to identify something through its mao (貌), its describable characteristics. This could very well have been conceived as a form of object identification through the connotations of a name,
} 
There are other tests for intensionality, of course, but the method of interchanging equivalent expressions seems to be the most widely mentioned. If co-referential terms, co-extensive predicates, or logically equivalent sentences are intersubstitutable without a change of truth value, then the linguistic context in which they occur is extensional; if not, then it is intensional. More often than not, however, we find the Mohists weighing the consequences of interchanging predicates that are not coextensive, but which bear some other obvious logical relation. For instance, if Jack is riding a horse, then Jack is riding an equine animal. In this case we substitute the predicate 'equine animal', whose extension is the set of all equine animals, for the predicate 'horse', whose extension is the set of all horses. No fallacy is committed here, in part because the context created by the verb 'rides' is extensional. However, if Jack is thinking of a horse, then it may or may not follow that he is thinking of an equine animal. Perhaps he does not know what an equine animal is.

The inference that the Mohists seem to be presupposing here is the substitution of a predicate $G$ for a predicate $F$ whenever the extension of $F$ is a subset of the extension of $G$. Evidence for the Mohists' interest in logical operations of this kind is apparent from a number of different examples found in the Canons. For example, there is an important earlier passage from the reconstructed text entitled Names and Objects $(N O)$ by A.C. Graham. In spite of apparently missing fragments and probably a number of textual errors, the principal message of this text appears clear. I reconstruct it as follows, filling in only those missing remarks that seem clearly intended:

Knowing is different from thinking... [Thinking of a huang is not thinking of a jade thing]; it is [thinking of] a huang that happens to be a jade thing. Thinking of a pillar is not thinking of a wooden thing; it is thinking of a pillar that happens to be a wooden thing. Thinking of a man's finger is not thinking of a man; [it is thinking of a finger that happens to be part of a man]. [Thinking of a bird is not thinking of a game animal]; it is thinking of a bird that happens to be a game animal. ${ }^{9}$

such as ' $g o u$ ' (狗, dog) or 'quan' (犬, canine), which were thought to be different. They distinguish this notion from a more basic form of intelligence that is the means by which one knows (cai 材), which the Mohists seem to think involved a variety of things associated with the apparatus of sense, such as being able to individuate an object in one's visual field by means of perceptual acquaintance with it. If this is correct, then the assertion at B40 of the Canons is reasonable. Jill could assert truthfully of Jack that Jack knows what a dog is, even if Jack fails to know the name 'dog' or the meaning of 'dog', as acknowledged by convention. It may be unclear to what extent object individuation in perception requires the mastery of a language, but a basic ability to do this is certainly possible for anyone who does know a language, even when certain words are absent from one's vocabulary. If, therefore, one knows dogs in the sense of 'zhi gou' (知狗), by means of perceptual acquaintance with dogs, then one also knows canines (zhi quan 知犬) by the same act of perception. This interpretation of B40, which resolves the apparent inconsistency, is certainly preferable to Zong's and others', since it is corroborated by other textual evidence and does not require any textual emendation.

${ }^{9}$ This passage has been reconstructed from $N O 3$, which I present here in full: “智與意異。 ... 是璜也 是玉也。意楹非意木也, 意是楹之木也。意指之人也非意人也。意獲也乃意昺也。” As given, the text is badly corrupted and no interpretation of it can stand beyond controversy. I have used brackets in the English translation to indicate places where the text seems to be missing. The account I have given here seems consistent with both the extant fragments of the passage and a number of logical insights 
The relevant logical notions here are those either involving or presupposing intersubstitution. The Mohists appear to be asserting, for instance, that in spite of the fact that all huang are made of jade, it does not follow from one's thinking of huang that one is thinking of a thing that is made of jade, for one might have no knowledge of jade as such, a distinct mineral. ${ }^{10}$ Here we seem to have evidence for an instance of intensionality in the verb phrase 'thinking of', but it is evident not from the intersubstitution of co-extensive predicates, but from the intersubstitution of the predicate 'thing made of jade', whose extension is the set of all things that are made of jade, for the predicate 'huang', whose extension is the set of all huang.

Now, it must be noted that as a test of intensionality this inference form is problematic. It successfully draws our attention to some contexts that are referentially opaque but misleads us on others. For instance, suppose that Jack eats meat from every kind of cow, but not from every kind of mammal. We substitute the term 'mammal' for the term 'cow' to obtain a false statement from a true one. Yet no expression in the sentence 'Jack eats meat from every type of cow' appears intensional. ${ }^{11}$ Moreover, restrictions on this rule to simple verb phrases without the universal quantifier do not solve the problem; any simple predicate with a transitive verb has a predicate nominal that admits of a quantificational interpretation, and this interpretation can be exploited to achieve the appearance of referential opacity by interchanging the right non-coextensive terms. Suppose that Jack rides horses, but not elephants. Then the sentence 'Jack rides elephants' is false, but we can produce a true statement from this by substituting the expression 'mammals' for the expression 'elephants', since all horses are mammals. It makes no difference whether the predicate nominal is interpreted as a universal quantifier or an existential one. Either way, the Mohists face difficulties in the application of their rule, if their purpose is indeed to ferret out cases of intensionality and distinguish them from those that are non-intensional.

Yet, for all that, the Mohists may not have been misguided here. More common tests of intensionality are problematic as well, and for similar reasons. The method of intersubstituting co-extensive predicates may fail to reveal forms of intensionality that are obvious by other methods. Consider the word 'needs'. If a baker needs some baking soda, then he also needs some sodium bicarbonate. The substitution of 'sodium bicarbonate' for 'baking soda' does not alter truth value. In spite of this, 'needs' is intensional at least in this context, since existential generalization, another common

apparent in other writings in the Canons that are better preserved. Of critical interest here are the selfcontained remarks on the method of disputation that we find in NO12-18. I address these passages in detail in section 4.

${ }^{10}$ The Mohists may also have been right about this from another point of view. It may have been a mere contingent fact that all huang are made of jade. If so, then no conclusions about the substance of huang would be warranted from the mere facts that one is thinking about huang and that all huang are (contingently) made of jade, since one could be thinking about a huang that happens to be made of some other mineral, or something else.

${ }^{11}$ This problem was first made known to me in an excellent review of an earlier draft of this paper by an anonymous reviewer for this journal. I have used the same example provided by the reviewer. 
test of intensionality, may fail to apply: the baker may need some baking soda even when none is available. Existential generalization, furthermore, has its own problems. Consider 'Jack feeds pigeons whenever he sees them.' We generalize on the term 'pigeons' to obtain the existentially-quantified assertion 'There are some pigeons that Jack feeds whenever he sees them', but this would be false if there were no pigeons. This seems to be a false positive result, since no term in this sentence appears intensional. $^{12}$

More importantly, the method of interchanging co-extensive terms also gives misleading results if we admit expressions that are interpreted non-compositionally, and natural language is full of them. If referential opacity really is the true mark of intensionality, then any expression consisting of two or more words that is interpreted non-compositionally will be intensional. This includes compound expressions of various kinds, such as 'white collar' and 'four wheel drive' in English, and ' zui-ying' (argumentative) in Chinese, and any expressions that are irreducibly idiomatic, such as 'cut to the chase'. Jill may take the advice of her friend with a grain of salt, but she would not be doing the same with a grain of sodium chloride. Or Jack may be considered over the hill because he just turned 50, but he would not be considered over a natural elevation of the Earth's surface because he just turned 50. Truth value changes in these cases, not due to the meanings of terms like 'take' and 'considered', but because of the idiomaticity of the expressions 'with a grain of salt' and 'over the hill'. Moreover, the intensionality of such phrases may not be apparent if we are considering only co-extensive expressions. Many terms that are constituents of idiomatic phrases in natural language may be ignored because terms that are strictly co-extensive with them are not forthcoming (they may have different shades of meaning), and many idiomatic phrases in natural language are not obviously idiomatic. $^{13}$

Awareness of these other forms of intensionality opens up new avenues for the interpretation of Mohist texts. If the Mohists had been aware that referential opacity could be caused by any expression that can be interpreted non-compositionally, and that any word or phrase could serve as a constituent of an idiom regardless of its meaning, then they would not have had any reason to believe that a sharp distinction could be drawn between intensional and extensional phenomena in natural language. Intensionality could not have been explained simply as a byproduct of assertions about the mind, and they would not have felt any need to talk about "intensional objects" and

\footnotetext{
${ }^{12}$ A conditionalized interpretation of this statement in first-order logic, with the antecedent representing 'whenever he sees them', would not have the same problem, but this would presuppose certain rules of translation, which are not given. I am simply pointing out here that we cannot assume an unproblematic intersubstitution of terms in natural language without further rules to handle contingent expressions such as these.

${ }^{13}$ Consider the interrogative 'Could you pass me the salt?' which is used to make a request. Most people would not respond to an utterance of this in the same way as they would to the sentence 'Do you at present have the physical ability to pass me the salt?' For a notable paper on the idiomatic features of indirect speech acts, see Searle 1979, 59-82.
} 
such. On the whole their attitudes toward language would have been far more inquisitive and adaptable.

If this is correct, then it casts new light on the aims that motivated the assertions at NO3. It is not that the Mohists regarded 'thinking of' as a fundamentally intensional verb-somehow intensional in isolation; it is rather that they felt that its contribution in connection with other phrases gave rise to various kinds of idiom in assertions, and this forced them to re-evaluate their admissibility. They were not thinking simply analytically; they were assimilating and evaluating linguistic complexes in wholes. Of course, my interpretation of this passage is debatable, but there is ample textual evidence in support of the view that the Mohists were concerned with idiomaticity as a basic explanation for at least some forms of intensionality. In the next section I will discuss some of the more striking cases in support of this.

\section{INTENSIONALITY RECONSIDERED}

Thus far our considerations have dealt mostly with rather standard forms of intensionality, those engendered by the complications of linguistic expressions involving mental states-'knows', 'thinks of', 'believes', 'loves' and the like. But intensionality can be caused by other things as well, linguistic phenomena having nothing to do with the mind. If the Mohists were not fully aware of this, then they were at least disinclined to believe that the properties of intensionality must somehow track the ontology of the mind. Consequently, with the absence of this constraint in their logico-semantical methodology, they had a greater inclination to weigh the consequences of combining and intersubstituting expressions in a variety of different linguistic contexts. This led them to a number of insights into the logic of natural language that went entirely unnoticed, as far as I can tell, in the early traditions of the West.

Surprisingly, in his otherwise careful examination of Mohist logic, Zong entirely misses this general point. Zong discusses a variety of intensional verbs used in the Canons that make plain the Mohists' concern with intensionality, but he interprets every one of these verbs epistemically. As a consequence, he neglects the Mohists' distinct contributions to the study of language:

[A] modern logician ... is unlikely to be impressed by what I have presented [in these examples]. After all, these are some particular forms of fairly simple modal inferences the nature of which modern logicians know only too well. But my concern here is the history of philosophy, not logic per se. ... The examples show that Mohist scholars clearly distinguished two kinds of contexts, one that involves intensional terms such as 'knowing', 'thinking of', and 'believing', and one that does not. (Zong 2000, 213)

Zong's oversight here consists in a failure to recognize the possibility that intensional contexts may be created by non-epistemic or non-mental terms or expressions. Whether or not modern logicians are likely to be impressed by the examples he gives, Zong is incorrect, I believe, in thinking that the Mohists were 
preoccupied only with forms of intensionality that are engendered by the conceptual problems associated with mental states. They were concerned with more general problems of meaning that arise out of the concatenation of a variety of terms in classical Chinese, and this made them more receptive to other forms of intensionality.

Chief among these forms are those involving idiomaticity, as noted in the previous section. The most striking examples are found in the Xiao-Qu, the largely selfcontained treatise of the Canons that makes up the latter portion of Names and Objects. In NO15, for instance, the Mohists are particularly interested in patterns of reasoning they refer to as mou (侔, parallelizing). The Mohists' idea is to evaluate and categorize expressions by investigating how meanings change when strings of characters consisting of ordinary statements of identity or predication are supplemented with other characters or strings. To do this, one reasons by bi ci er ju xing (比辞而俱行, comparing expressions and letting them proceed). It is unclear what much of this entails, but at least some of these patterns of reasoning involve proceeding from statements of the form 'An $A$ is a $B$ ' to those of the form ' $V A$ is $V B$ ', where $V$ is a verb combined with the noun phrases $A$ and $B$ to yield, in effect, two distinct nominalized infinitives. When these patterns of reasoning successfully advance from one proposition or expression to another without contravening its admissibility, the Mohists say that they xing 行 (proceed) and refer to them as shi er ran (是而然). In such cases we may correctly assert ' $V A$ is $V B$ ' on the supposition that an $A$ is a $B$. When they do not successfully advance in this way, they are referred to as shi er bu ran (是而不然), and the Mohists assert ' $V A$ is not $V B$ ' as a consequence.

Each of the assertions considered in NO15 involves an intensional transitive verb exemplifying the basic principle shi er bu ran (是而不然) in which reasoning from a statement of the form ' $A n A$ is a $B$ ' does not successfully advance (or xing 行) to a statement of the form ' $V A$ is $V B$ '. The passage offers eleven uses of transitive intensional verbs. Of these eleven, five are straightforwardly or arguably non-epistemic, or more generally, non-intentional (-with-a- 't'): 'cheng' (乘, riding), 'ru' (入, entering), 'duo' (多, abounding in), 'wu' (无, being without), and 'sha' (杀, killing). The most striking of these is the last, since 'killing' would ordinarily be thought of as an extensional verb. Regarding this verb, the Mohists assert the following:

(8) 盗人人也... 杀盗人非杀人也。 Robbers are people... but killing robbers is not killing people.

This is striking, of course, because almost anyone trained in Western symbolic logic will consider it obvious that the contrary statement 'Killing robbers is killing people', or at least something equivalent to it, is provable in first-order predicate logic, if we allow the assumption that all robbers are people, that is,

(9) $(\forall x)(\operatorname{Robber}(x) \rightarrow \operatorname{Person}(x))$ 
The statement 'Killing robbers is killing people' need only be transcribed as follows:

$$
\begin{aligned}
& (\forall e)(\operatorname{Killing}(e) \&(\exists x)(\operatorname{Robber}(x) \& \operatorname{Object}(x, e)) . \rightarrow .(\exists x)(\operatorname{Person}(x) \& \\
& \operatorname{Object}(x, e))
\end{aligned}
$$

I am assuming here, as above, that we are quantifying over events, and that the expression 'Object $(x, e)$ ' is to be understood as: " $x$ is the object of event $e$."

Apparently, what the Mohists would object to here is our decomposition of the expression 'killing robbers' into a conjunction of individualized predicates. They seem to have felt that the combination of the ideographs 'sha' (杀, killing) and 'dao ren' (盗 人, robbers) formed an idiom that was recognized as a distinct, unanalyzable unit of common speech. This unit of speech carried with it connotations of justified execution, so that, at least for some people in the linguistic community in which the Mohists lived, the expression 'sha dao ren' (杀盗人, killing robbers) was simply intended to mean "justified execution of criminals". By contrast, connotations of justified execution were not considered present in the meaning of the expression 'killing people', which seemed to connote more simply an act of murder. Indeed, the Mohists explicitly prohibited the latter in connection with their espoused doctrine of universal love (cf. NO17). ${ }^{14}$

My interpretation of these expressions is controversial. In the next section I respond to an important objection to it, but we can provide further evidence for it

\footnotetext{
${ }^{14}$ This idea is suggested by A.C. Graham $(2003,488)$. Graham, however, seems to view it as a sort of novelty, conceived by the Mohists more or less in isolation from their other semantical insights. Part of my purpose in this paper is situate Graham's basic idea in the framework of a more comprehensive theory that explains the Mohists' general semantical program, their interest in intensionality, and their skepticism about the compositionality of language. For a proposal alternative to Graham's, see Mou 2009. As I understand it, Mou's account is only partly in disagreement with mine. It appeals largely to phenomenological facts about the way in which our attention shifts among different aspects of things in different contexts of communicative discourse. For example, Mou argues that "we often shift our attention from what is shared between involved parties ... to what is distinction between [them]... depending on the nature of the context and concrete situation." To explain the killing robbers case, Mou proposes the following: "[W]hen saying 'robbers are people', one focuses on the aspect of robbers, A, that makes them being people; nevertheless, when saying 'killing robbers is not killing people', one's focus shifts to some other aspect of robbers, $A^{*}$, which is possessed by robbers rather than by the other people and which makes robbers deserve being killed (from the Mohist point of view, and cited for the sake of argument): killing robbers for the sake of $\mathrm{A}^{*}$; that does not amount to killing people for the sake of $\mathrm{A}^{*}$ because people generally speaking do not possess $\mathrm{A}^{*}$." Unfortunately, Mou does not further explain what he means by $\mathrm{A}^{*}$, but this may be irrelevant. What matters here is whether Mou's phenomenological explanation of the process by which we grasp the various aspects of things in verbal discourse is compatible with my suggestion that the meaning of 'sha dao ren' (杀盗人, killing robbers) in classical Chinese was treated as idiomatic. As far as this is concerned, I don't see any disagreement. However, Mou does make some rather substantive metaphysical claims in connection with his account that I remain noncommittal about. He claims, for instance, that "such a shift in focus is not supposed to be made at random but has its due metaphysical foundation: an object of study really possesses its multiple aspects / layers / dimensions". My own account is essentially semantical, not metaphysical, and I regard it as compatible with a variety of different metaphysical views.
} 
simply by comparing it with other remarks in NO15 which more obviously indicate a preoccupation with idiomaticity. For instance, there is the curious use of the expression 'ru mu'入木 (entering wood) in the following line from $\mathrm{NO} 15$ :

(11)船木也，入船非入木也。

A boat is wood, but entering a boat is not entering wood.

Importantly, there is nothing in the meaning of ' $r u$ ' (入, entering) indicating, by itself, an intensional context; non-mental objects or entities surely have the capacity to enter things. As Zhang and Liu (2007) observe, the complex expression ' $r u$ mu' (入木) is idiomatic. It means "going to die", something entirely absent in the connotation of 'ru chuan' (入船, entering a boat), which is used to signify just the generic action of going into a boat. ${ }^{15}$ Note that the grammatical form of the expression 'ru chuan' (入船, entering a boat), which consists of a simple combination of two ideographs, is precisely the same as ' $r u$ $m u$ ' (入木, entering wood). But grammatical form is deceptive, as the Mohists knew, for it masks the contrast between analyzable compounds and expressions involving idiomaticity. Similar points may be made with regard to the remaining non-epistemic intensional transitive verbs.

In the remaining six cases we have assertions involving transitive verbs that are often regarded as intensional for epistemic reasons. But epistemic-based intensionality is not likely the problem the Mohists had in mind even with these. Consider the first item from NO15:

(12) 获之 (视) $*$ 亲人也, 获事其亲非事人也。 16

The father of huo is a human; and yet it does not follow from this that when huo serves his father, he is serving a human (or acting as a servant).

This example involves the transitive intensional verb 'shi' (事, serve). Now, contexts created by epistemic terms are generally considered opaque on the supposition that they may fail to support otherwise valid inferences owing to failures of knowledge. Jack may believe de dicto that the Evening Star is bright, but not believe the same thing about the Morning Star, if he fails to recognize that the two terms 'Evening Star' and 'Morning Star' designate the same astronomical body. Similarly, Jack may desire de dicto to learn about the Evening Star without desiring the same thing about the Morning Star, if (again) he fails to realize that the Evening Star is identical to the Morning Star. On the other hand, unless Jack is simply mistaken about basic facts, it is highly unlikely that he will fail to believe that he is serving a human if he knows that he is serving his father, for it is common knowledge that all fathers are human. It is for this reason that we should consider it implausible that the Mohists were worried about the possibility of huo's not realizing that his father was a human. The Mohists were not

\footnotetext{
${ }^{15}$ Zhang and Liu 2007, 85-102.

${ }^{16}$ The text here has been emended by A.C. Graham $(2003,487)$. The notation '(Y)*X' is: "Read X for Y."
} 
assuming that the context created by the transitive verb 'shi' (事, serve) is intensional for reasons involving possible failures of knowledge. It is much more likely that they were concerned that the phrase 'shi ren' (事人, serve a human) was commonly interpreted as an idiom signifying the poor labor involved in being a servant, something they didn't feel was apparent in the connotation of the phrase 'shi qi qin' (事 其亲, serve one's father). ${ }^{17}$

Arguably, the same point is true of the example in NO15 that immediately follows (12):

(13)其弟美人也，愛弟非愛美人也。

One's brother is a handsome man; and yet it does not follow from this that when one loves one's brother, one loves a handsome man.

It is implausible, in my opinion, that the Mohists were worried here about the epistemic-based intensionality of the term ' $a i$ ' (爱, love). It is conceivable, of course, for one to fail to recognize the handsomeness of one's brother, as perceived or acknowledged by others. A better account, however, is that the Mohists were concerned with the idiomatic force of the complex expression 'ai mei ren' (愛美人, love a handsome man), which, in the great economy of classical written Chinese, may well have involved connotations of sexual attraction. One's brother may be a handsome man, but loving one's brother does not imply that one is sexually attracted to him. The intensionality here that undermines the suggested inference is not engendered by the single term ' $a i$ ' (爱, love), but by the unique way in which the meaning of the string ' $a i$ mei ren' (愛美人, love a handsome man) is determined idiomatically.

Indeed, if the Mohists really were concerned with possible failures of knowledge in the passage at NO15, then surely they would have used more obvious and convincing examples - assertions not hinging on an ignorance of basic facts like "fathers are people". They would have used examples where it is clearly more likely that one could fail to recognize certain identities, analogous to those inspired by Frege's Morning Star-Evening Star scenario. Moreover, they would likely have felt the need to distinguish epistemic forms of intensionality from idiomatic ones, something we do not seem to find any indication of in NO15 or anywhere elsewhere in Names and Objects. Whatever the case, any sharp contrast between intensional and non-intensional terms seems to me entirely antithetical to what appears to be a far more fluid and adaptable conception of natural language emerging out of Names and Objects that is perceptive of the many different ways in which meanings are grasped in ordinary communicative discourse. This very fluid and adaptable conception of language is precisely what makes later Mohist logic philosophically significant, and-dare I sayoriginal in the investigation of intensionality. The Mohists give us good reasons to avoid any blanket assumption about the compositionality of natural language, and I am

\footnotetext{
${ }^{17}$ As with the expression 'killing robbers', I am following the suggestion of A.C. Graham on this point $(2003,486)$.
} 
inclined to say that many contemporary Western philosophers, logicians notwithstanding, have important things to learn from them. ${ }^{18}$

\section{OBJECTIONS AND REPLIES}

A common view of the Mohists' logico-semantical program is that it was motivated by little desire to demarcate the kinds of formally valid inference patterns that are characteristic of Aristotelian categorical logic. The reason often given is that the Mohists had a more basic interest in the semantics of compound expressions that distracted them away from the issue of logical form. This interest in semantics was pursued in the context of a largely unsystematic program of analogical disputation that involved categorizing linguistic forms into different classes on the basis of their underlying semantical properties. The categorization of these forms proceeded by examining parallels in phrasing and making judgments about their kind on a case-bycase assessment of their admissibility. Distracted by their own idiosyncratic methodology, the Mohists failed to classify linguistic forms in the way that Aristotle did, independently of their semantical content, and this undermined any desire they might have had to develop a syllogistic-style logic of categories.

A view of this kind is proposed by Chris Fraser. Fraser suggests that the Mohists were skeptical of the utility of studying purely formal methods because their own technique of drawing inferences based on mere formal linguistic parallels was "invariably unreliable". As a consequence, they had little desire to develop a working theory of logical form:

Over-reliance on formal parallels tends to yield assertions that violate what the Mohists take to be the norms for distinguishing various kinds ... and predicating the corresponding terms. When this happens, they reject these assertions on the basis of their knowledge of the semantics of terms, which they take to be more fundamental than linguistic structure or logical form. Their discovery of the misleading nature of linguistic parallels probably contributed to their skepticism about the extent to which formal methods could be applied in dialectics or disputation... This skepticism may in turn have helped point them away from any significant study of formal logic, but in fact their inquiries were oriented in a different direction from the start. (Fraser 2009)

Fraser is certainly right, I think, in making the general claim that the Mohists' skepticism about the utility of formal methods was a consequence of their recognition

\footnotetext{
${ }^{18}$ It is not clear to me whether the Mohists thought that most linguistic contexts are intensional, or whether they felt that intensional phenomena simply make up an important minority that ought to be of concern to anyone engaged in the art of disputation. The treatise Names and Objects (reconstructed by Graham) simply surveys a number of different possibilities, some extensional and some intensional, and admonishes the reader to be "cautious" when making inferences based on grammatical parallelisms in language. Whatever the case, the Mohists' preoccupation with intensionality was enough, I believe, to make them skeptical about role compositionality in language, and we do not see this perspective being entertained with the same degree of interest anywhere in the early philosophy of the West.
} 
of the misleading nature of linguistic parallels. On the other hand, he seems to lose sight of this as a real contemplative discovery - in spite of his use of the word. In explaining why the Mohists draw the conclusion that killing robbers is not killing people, Fraser proposes that the Mohists had in mind little more than an expedient semantical invention: they simply stipulated that killing robbers is not killing people out of an ad hoc attempt to reconcile their approval of the execution of criminals with their doctrine of inclusive concern. This allowed them to go on advocating the absolutist view that killing people is always wrong, even when offering their nod of approval in sight of a criminal's execution. Indeed, the Mohists do seem to have believed that they could justify their ethical views merely by drawing their opponents' attention to certain facts (or claims) about the semantics of compound expressions. ${ }^{19}$ But as a tactic of moral justification, this seems dubious. In Fraser's view, even granting that executing criminals is not the same thing as murder, it is "still an event in which people are killed". In other words, the Mohists were abandoning commonsense, illicitly attempting to support their position on inclusive concern by denying what others would take to be obvious, that the killing of a robber is indeed the killing of a person. Granting the oddity of this, the Mohists could have simply distinguished different kinds of events, some specific, and some general. In Fraser's words:

They could have pointed out that 'killing people' refers generally to all kinds of actions in which one person causes another to die. These include a range of more specific kinds of actions, among them intentional, morally wrong killing of the innocent (murder) and communitysanctioned, morally justified killing of criminals (execution). Thus killing robbers could be an action of the kind killing people without being one of the kind morally wrong killing. (Fraser 2009)

Why didn't they do this? Fraser's answer is that "this route didn't occur to them" - they were simply unable to move beyond the assumption that every name in language corresponds to exactly one distinct thing, as later classical thinkers did. That is, the Mohists simply assumed that "each unit of language should denote some discrete kind (lei), or part of reality...", and this led them into the awkward situation of being unable to distinguish terms of different scope, some of whose extensions fall within others.

Yet the charge that the Mohists failed to differentiate terms of different scope is simply incommensurate with the existing textual evidence. How else are we to make sense of their more basic claim that all robbers are people-if not on the assumption of

\footnotetext{
${ }^{19}$ True, the Mohists may have been simply naïve in attempting to justify moral judgments by an appeal to an inventory of basic semantical categories. Yet this has no direct bearing on the issue of whether the Mohists were right in asserting in their native tongue that killing robbers is not killing people. Our concern here is with their assertion's logical form, as it was grasped by listeners of the era in which the Mohists were advancing their philosophy. To the extent that the Mohists were grappling with a great variety of compound expressions of varying degrees of idiomaticity, they were never inclined to take the principle of compositionality for granted. This forced them to cast about for other methods of argument, and this we see reflected in their very attempt to produce a taxonomy of semantic relations among basic expressions.
} 
some analogy to the set-theoretical fact that the set of all robbers is a subset of the set of all people? If the Mohists failed to differentiate terms of scope, then they would have to have believed it necessary, too, to treat the terms 'dao ren' (盗人, robber) and 'ren' (人, people) as denoting two disconnected kinds or parts of reality. That would have forced them to deny the admissibility of the claim that all robbers are people and many others besides ('Jill's parents are people', 'Her brother is a handsome man', 'Carriages are wood', and so on). But they did not do this. It cannot be a coincidence that the majority of parallelisms investigated in the Xiaoqu involving the intersubstitution of terms in intensional contexts appeal to logical relations whose explanation naturally invokes the notion of extensions overlapping or falling within one another.

Indeed, in the alternative proposal quoted above, Fraser is ignoring precisely what he is willing to attribute to the Mohists elsewhere, that "killing people" was conceived in ordinary discourse in connection with acts of murder, the unjustified killing of innocents. This is understandable; in English the expression lacks the idiomatic force that we can say was likely ascertained by members of the Mohist community, who were living in ancient China and dealing with an ideographic language of extreme economy. In any case, the Mohists were not simply stipulating this; they were noting an obvious empirical fact about linguistic usage in ancient China and attempting to exploit it in their justification of the doctrine of universal love. If they had simply stipulated this, then they would have been accused of violating or otherwise abandoning the norms of speech. Admittedly, the difference between stipulation and genuine analysis may be vague. Many words have a variety of meanings, and many are polysemous. A proposed analysis of these words may provoke agreement in some circles and disagreement in others, and in fact the Mohists' own analysis of the Chinese expression for "killing robbers" seems to have aroused a certain amount of disagreement from members of the common community (cf. NO15). However, it would be entirely uncharitable to conclude from this that the Mohists didn't care about the norms of speech and were willing to stipulate meanings as they pleased, whether common or not. For their arguments to have appeal, they surely would have felt the need to identify some common ground with those they sought to convince; they would have observed the common idioms of important terms carefully for the purpose of winning over otherwise indecisive minds in argument.

Thus, the meaning of the whole was not resolvable into the meanings of the parts, so the extension of the expression 'sha ren' 杀人 (killing people), conceived as an unanalyzable linguistic unit, would have been none other than:

\section{(14) $\{x \mid x$ is an unjustified killing of innocents $\}$}

When we assume that this is the ground of the common idiom, and the extension of 'sha dao ren' (杀盗人) is $\{x \mid x$ is a justified killing of robbers $\}$, then it follows, trivially, that killing robbers is not killing people. The conditions that satisfy these two predicates are not the same. The Mohists could easily have held this view while 
allowing that terms may be distinguished by their scope, with some being more general than others. They may have held that the extensions of these phrases are subsets of some more general set identified by any kind of action in which, say, a living being caused to die. ${ }^{20}$ But these possibilities are only appreciated when it is remembered that the compositionality of classical Chinese cannot be taken for granted, since the concatenation of ideographs in this language can produce expressions whose meanings are not the mere sums of the meanings of their constituent parts.

If the Mohists did not develop an Aristotelian-style logic of formal inference patterns, it is because the semantics of classical Chinese is in many ways resistant to analyses that presuppose compositionality. But this is not a failing on their part. Rather, what we find in the Canons are insightful responses to dilemmas that are faced when reasoning in the context of a language whose basic elements exhibit, in combination, varying and unpredictable degrees of idiomaticity. In this regard, the explanation I am proposing here has the benefit of better explaining the peculiar nature of the Mohists' investigations of language and their unique concern with the development of techniques of analogical argumentation. Specifically, the Mohists' insistence on classifying various expressions on the basis of their consideration of the properties of nominalized infinitives would have been entirely unpersuasive as the basis of philosophical argument if it were not for the fact that there were genuine similarities and differences in the meanings of these infinitives that members of the broader population outside the Mohists' philosophical community would have been willing to recognize. No charitable interpretation of Mohist literature would assume that the Mohists lacked the insight to realize that a mere stipulation that "killing robbers" is different in kind from "killing people" would fail to convince any reasonable interlocutor to change his or her views about the ethics of justified execution. ${ }^{21}$

\footnotetext{
${ }^{20}$ This is, to be sure, a matter of speculation, and I have not identified any textual evidence in support of it. However, if the Mohists really were making observations on common idioms, then they probably would not have felt it necessary to point this out, for their argument could have easily been made without doing so. In effect, I am offering what I take to be an inference to the best explanation: the best (and most charitable) explanation of the Mohists' arguments in NO15 and elsewhere is that they had something like this in mind. It is the best explanation because it represents the Mohists' method of argument as an inherently reasonable one, unlike any account that assumes that they were in the business of making arbitrary stipulations of meaning.

${ }^{21}$ It might be claimed that since, in my view, the Mohists rejected the possibility of articulating a principled distinction between intensionality and extensionality, I should agree with Fraser that they must have felt a need to make stipulations about critical expressions to advance their views. I disagree. I take the Mohists' rejection of this to imply that they rejected the possibility of identifying any general features in the grammar of classical Chinese that would have enabled them to distinguish one from the other on the basis of mere grammatical form. Note that grammatical form can reveal itself in many ways. In English it is identified partly through properties of inflection, which are absent in classical Chinese. In the latter, it is primarily the ordering of ideographs in a grammatical sequence that bears the burden of revealing differences in grammatical form. Now, the language of English, it should be noted, is no different from classical Chinese in this regard. Here, too, we seem to encounter serious difficulties in drawing a principled distinction between intensionality and extensionality merely on the basis of grammatical form. If Jack is riding a horse, then there is some horse that Jack is riding. However, if Jack is imagining a horse, then we cannot conclude that there is some horse that Jack is imagining. We seem
} 


\section{CONCLUDING REMARKS}

I mentioned at the beginning of this paper that the insights of the Mohists reveal obvious and important limitations in any technique of analysis that is uncritically applied with a decompositional approach in mind. It is now time to clarify these limitations. We have seen that an analysis of natural language concatenation in terms of predicate conjunction is questionable for a very large variety of expressions in both classical and modern Chinese. That the Mohists were especially concerned with this is obvious from their discussion of mou (侔, parallelizing), where concerns about compositionality come to the fore. With an admirable degree of lucidity, they realized that arbitrary combinations of ideographs in Chinese, such as the joining of verbs with nouns to yield nominalized infinitives, cannot be uncritically assumed to produce complex expressions whose meanings are determined merely by the meanings of their parts and their modes of combination. This awareness of the problems of

to have a discrepancy in logical form, but this discrepancy is not exposed in the grammar, for the sentences 'Jack is riding a horse' and 'Jack is imagining a horse' appear to have the same grammatical form. This puzzle is simple to apprehend, but early philosophers of language in the West do not seem to have been aware of it. Instead, we find them assuming that we can identify the logical form of a sentence primarily through its grammar, as in the case of the syllogistic logic of Aristotle. The idea there was to identify the form of an argument (and therewith its sentences) by examining its logical content and by ignoring its non-logical content. The former was thought to be identified through certain elementary logical notions ('all', 'some') in connection with basic properties of grammatical form, those associated with relations between subjects, copulas, and objects. Hence, from the sentence 'All humans are mortal' we obtain the sentence schema 'All $A$ s are $B \mathrm{~s}$ '. This operation, which exploits basic features of grammatical form, was thought to draw out the logical form that is otherwise implicit in a sentence's meaning. In later Mohist literature we do not observe a similar preoccupation with identifying general principles of logical form because the Mohists were skeptical about it from the start: they were aware of too many counterexamples that frustrated the very idea of identifying a logical form from a grammatical one. So they admonished caution on the matter of making inferences on the basis of parallelisms in grammar and rejected any general distinction between intensionality and extensionality. This does not mean, on the other hand, that they had no reason to look for common idioms and other conventions recognized in ordinary discourse. One may consistently reject a principled distinction between intensionality and extensionality while observing that our ordinary speech is abounding in common conventions that determine on a case by case basis how expressions are to be understood. There is no difference in grammatical form between the expressions 'he kicked the container' and 'he kicked the bucket', yet the latter in today's English, unlike the former, will often be taken as an idiom meaning "he died". We cannot determine this idiomatic meaning simply by examining its grammatical form, or by identifying the meanings of the words and the way in which they are combined compositionally. Consequently, we cannot rely on the properties of grammatical form to tell us that this expression is to be interpreted non-extensionally. Yet its idiomatic meaning is there nonetheless; it is recognized and supported by the conventions of use. In my view, the Mohists were simply trying to exploit conventions of this sort to support their arguments. The Mohists' assumption was that those who felt some of the force of the common idiom of 'killing robbers' would have been more likely to concede to the Mohists' views on the ethics of justified execution if they realized (as the Mohists wanted) that they themselves had a disposition to reason similarly with other patterns of expressions of similar form, such as those found in $N O 15$. 
compositionality led them to an understanding of the phenomena of intensionality and idiomaticity that went largely unappreciated (so far as I know) in the early traditions of the West.

It is noteworthy that classical Chinese's modern counterpart, which has inherited a great deal from its predecessor, is highly idiomatic and retains many of the features that resist compositional analyses that can be found in its earlier forms. This of course is evident from the sheer numerousness of Chinese cheng-yu (成语, set phrases). However, beyond these we observe a wide spectrum of semantical possibilities among compound expressions that resist any simple scheme of classification, not simply among nominal compounds but among most other types as well. Verb-object compounds, for example, exhibit varying degrees of idiomaticity in agreement with the extent to which their constituents are grammatically separable in context. ${ }^{22}$ The meaning of the verb 'zou xue' (走穴, to earn extra money as a part time entertainer by performing in many venues) is highly idiomatic and irreducible to the meanings of its constituent parts, 'zou' (走, to walk) and 'xue' (穴, cave, hole). For this reason it does not support a grammatical separation of its constituents, as do the readily separable verb-object compounds 'shui jiao' (睡觉, to sleep) and 'shuo huang' (说谎, to lie), which are essentially non-idiomatic. Thus, the following are grammatical:

这一觉, 睡得真好。

I had a really good sleep.

这个谎我们不能说。

This lie we cannot tell.

However, no such parallel construction is possible for the expression 'zou xue' (走 穴), in which the second constituent of the compound is detached from its partner and placed in the sentence-initial position. What makes this contrast problematic for the thesis of compositionality is the fact that there are rather nebulous cases in between: phrases which allow for limited degrees of grammatical separability and which exhibit lesser degrees of idiomaticity. An example is ' $g e$ ming' (革命, revolution), the meanings of whose constituents ' $g e$ ' (革, remove the mandate) and 'ming' (命, life) do seem to be faintly involved in the connotations of the whole; but the whole, which is still largely idiomatic, supports only highly limited forms of grammatical separation. ${ }^{23}$ Another example is 'shang feng' (伤风, catch a cold), which does not support sentences in which the second constituent occurs in the sentence-initial position, but which does

\footnotetext{
${ }^{22}$ For further discussion of this, see $\mathrm{Li}$ and Thompson 1989, 73-81. Most of these examples are from $\mathrm{Li}$ and Thompson; the exceptions are 'zou xue' and 'ge ming'. Li and Thompson do discuss 'ge ming', but they treat it as irreducibly idiomatic, whereas I think that the meanings of the parts do play some role in the determination of the meaning of the whole. I thank Bo Mou for his comments on this point.

${ }^{23}$ An example of this separation, suggested to me by Bo Mou, is 'wo men jiu shi yao ge ni men de ming' (我们就是要革你们的命, We insist that we reform your practices).
} 
support constructions involving more limited forms of separation. Thus, whereas (18) is ungrammatical, (18) and (19) are acceptable forms of speech:

*风, 伤了。

*A cold, he caught.

(18) 他伤了风。

He caught a cold.

(19) 他伤大风了。

He caught a terrible cold.

What we learn from these points is not just that there are some Chinese linguistic phenomena that are impervious to the application of the analytical techniques we described above. As the Mohists knew, it is that no definite criteria are possible for determining which of these phenomena are amenable to a decompositional analysis, and which are not. We cannot, in other words, outline categorical differences here. We have, on the whole, broad spectrums of compound phenomena that admit of no precise points at which expressions whose meanings are determined entirely through their constituent parts and their combination can be distinguished from those whose meanings are essentially idiomatic and recognized independently of the semantics of their parts.

This point is critical, because arguments for compositionality typically rely on the assumption that intensionality in natural language, in whatever form it occurs, is clearly identifiable and isolable, so that the meaning of any complex grammatical string that is not intensional is determined exhaustively by the meanings of its constituent parts and the structural mode of their combination. Abandoning this assumption, we are led to a more fluid conception of language. Apprehension of meanings in discourse may customarily proceed not merely combinatorially, through a tacit apprehension of the contributions of semantical building blocks and their overall form, but also holistically, by means of an appreciation of the idiosyncrasies of linguistic complexes, conceived more or less independently of their parts. And in the attempt to fully ascertain others' communicative intentions in ordinary discourse this conceptual shift between combinatorial and holistic modes of thought might very well occur episodically. This underscores the general belief that success in communication invariably depends on a heavy dose of inductive inference and inference to the best explanation, in addition to one's deducing, in accordance with the constraints of compositionality and the conventions of meaning, the literal meanings of sentences.

Though in their own way brilliant thinkers, the Mohists were not entirely unprompted in their desire to articulate a logic of intensionality. For there are, as I have argued, certain palpable features of classical Chinese, of both a semantical and syntactical sort, that led them into their investigations of intensional contexts and that served as a primary catalyst that inspired their own ambitious program of "rectifying 
names". As far as I know, the philosophical implications of these obvious features have not been sufficiently addressed in the literature in comparative philosophy, in spite of the fact that the lexical semantics of Chinese compound expressions has received substantial attention over the years in journals on Chinese linguistics. In any case, as a principle central to much of our efforts at analyzing the expressions of natural language, compositionality will have to be relegated in status to a rule of thumb. It can no longer be assumed a priori to hold of a definitive range of complex expressions that are classifiable on the basis of syntactical properties alone, and this implies that the syntax of compound expressions cannot be assumed to be an infallible guide to the meanings that correspond to them. This is not to say, on the other hand, that Western techniques of logical analysis are to be cast aside as irrelevant to the problems of Chinese philosophy, or to the issues that preoccupied the Mohists in particular. It is just that any application of them will have to accommodate greater flexibility than the principle of compositionality seems to allow. As the Mohists say, it will be necessary, in hazarding analyses of critical philosophical statements or positions, for us to "proceed with caution".

\section{ACKNOWLEDGEMENTS}

A shortened version of this paper was presented at the ACPA 2009 Shanghai Workshop at East China Normal University in June 2009. I especially wish to thank Bo Mou, Steven Geisz, and Chung-ying Cheng for their helpful comments, both during and after the workshop. I would also like to thank those on the editorial board of this

journal who reviewed an earlier draft of this paper for their meticulous evaluation and excellent comments and suggestions.

\section{REFERENCES}

Chen, Meng-lin (1983), Mo-Bian-Luo-Ji-Xui [Studies in the Logic of Mohist Disputation] (Ji Nan: Qi-Lu Publishing House).

Fraser, C. (2009), "Mohist Canons", in Stanford Encyclopedia of Philosophy, $<$ http://plato.stanford.edu/entries/mohistcanons/>

Graham, A.C. (1978; reprint edition 2003), Later Mohist Logic, Ethics, and Science (Hong Kong: The Chinese University Press).

He, Jing-lun (1971), Mo-Tzu-Jiao-Gu [An Emended Compilation of Mohist Writings]

(Taipei: Hua Lian Publishing House).

Kant, Immanuel $\left(1781 ; 2^{\text {nd }}\right.$ edition 1787), Kritik der reinen Vernunft; trans. Norman Kemp Smith (1965), Critique of Pure Reason (London: Macmillan).

Leibniz, G. (1686), Philosophical Essays; trans. Roger Ariew and Daniel Garber (eds) (1989) (Indianapolis: Hackett).

---- (1690), Philosophical Writings; trans. Mary Morris and G.H.R. Parkinson (eds) (1973) (London: J.M. Dent and Sons Ltd.). 
Li, C.N. and Thompson, S. (1989), Mandarin Chinese: A Functional Reference Grammar (Berkeley and Los Angeles: University of California Press).

Li, Yu-shu (1969), Mo-Bian-Xin-Zhu [New Studies on Mohist Disputation] (Taipei: Commercial Press).

Locke, John (1690), An Essay concerning Human Understanding; P.H. Nidditch (ed.) (1975) (Oxford: Oxford University Press).

Moore, G.E. (1903), Principia Ethica (Cambridge: Cambridge University Press).

Mou, B. (2009), "On Some Methodological Issues Concerning Chinese Philosophy”, in Bo Mou (ed.), History of Chinese Philosophy (London: Routledge), pp. 22-6.

Pietroski, P. (2000), "The Undeflated Domain of Semantics", in The Nordic Journal of Philosophy 1: 161-76.

Searle, John R. (1975), "Indirect speech acts", in P. Cole and J. L. Morgan (eds), Syntax and Semantics, 3: Speech Acts (New York: Academic Press), pp. 59-82.

Zhang, J., and Liu, F. (2007), "Some Thoughts on Mohist Logic", in Johan van Benthem, Shier Ju and Frank Veltman (eds), A Meeting of the Minds: Proceedings of the Workshop on Logic, Rationality and Interaction (London: College Publications), pp. 85-102.

Zong, Desheng (2000), "Studies of Intensional Contexts in Mohist Writings", Philosophy East and West 50 (2): 215-7. 